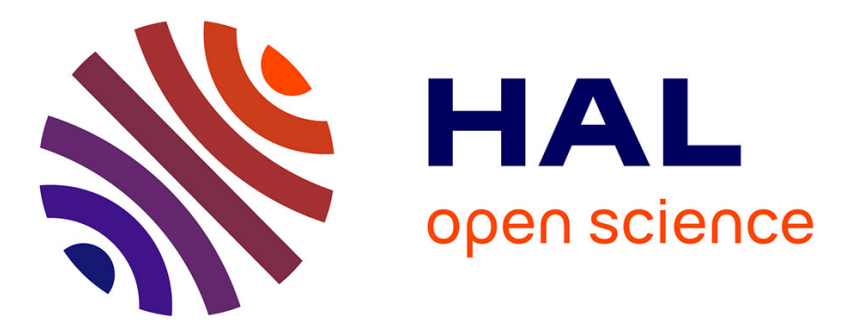

\title{
Reconfigurable CTS Antenna Fully Integrated in PCB Technology for 5G Backhaul Applications
}

\author{
Thomas Potelon, Mauro Ettorre, Laurent Le Coq, Terry Bateman, Jim
}

Francey, Ronan Sauleau

\section{- To cite this version:}

Thomas Potelon, Mauro Ettorre, Laurent Le Coq, Terry Bateman, Jim Francey, et al.. Reconfigurable CTS Antenna Fully Integrated in PCB Technology for 5G Backhaul Applications. IEEE Transactions on Antennas and Propagation, 2019, 67 (6), pp.3609-3618. 10.1109/TAP.2019.2902644 . hal-02135654

\section{HAL Id: hal-02135654 https://hal.science/hal-02135654}

Submitted on 8 Jul 2019

HAL is a multi-disciplinary open access archive for the deposit and dissemination of scientific research documents, whether they are published or not. The documents may come from teaching and research institutions in France or abroad, or from public or private research centers.
L'archive ouverte pluridisciplinaire HAL, est destinée au dépôt et à la diffusion de documents scientifiques de niveau recherche, publiés ou non, émanant des établissements d'enseignement et de recherche français ou étrangers, des laboratoires publics ou privés. 


\title{
Reconfigurable CTS Antenna Fully Integrated in PCB Technology for 5G Backhaul Applications
}

\author{
Thomas Potelon, Mauro Ettorre, Senior Member IEEE, Laurent Le Coq, Terry Bateman, Jim Francey \\ and Ronan Sauleau, Fellow IEEE
}

\begin{abstract}
We present the design and fabrication of a fully integrated continuous transverse stub (CTS)/pillbox antenna for 5G backhaul applications in E-band. The antenna contains 16 radiating slots excited by a corporate feed network in parallel plate waveguide (PPW) technology. These slots are divided into two subarrays of 8 slots, each one generating either a sum or a difference pattern along E-plane. Two pillbox systems are used to feed the two subarrays and therefore the radiation patterns can be steered in $\mathrm{H}$-plane. Such a reconfigurability both in $\mathrm{E}$ - and $\mathrm{H}$-planes has not been reported with CTS antennas. Moreover, the recentlyintroduced substrate-integrated PPW (SI-PPW) technology is used in printed circuit board (PCB) technology for a complete integration of the antenna module. The structure is thinner than 3 $\mathrm{mm}$, and only low-cost standard fabrication processes are employed for the prototype. The measurement results are in good agreement with simulations. In E-plane, the sum and difference patterns can cover an angular window of $\pm 10^{\circ}$, and they can be steered in $\mathrm{H}$-pane until $\pm \mathbf{1 4}^{\circ}$, in the complete E-band $(\mathbf{7 1 - 8 6} \mathrm{GHz})$. Over this frequency band, the measured difference pattern exhibits a null depth below $-23 \mathrm{~dB}$. The gain remains stable over the band with a maximum of $17.5 \mathrm{dBi}$ and a variation lower than $2.6 \mathrm{~dB}$.
\end{abstract}

Index Terms - broad-band antennas, high-gain antennas, inpackage antenna, parallel-plate waveguides, PCB technology, reconfigurable antenna, slot array.

\section{INTRODUCTION}

The demand for high-data rate for mobile communications has been growing exponentially since the installation of the first cellular network in the ' 80 s. To respond to this demand, new technologies have been developed and a new generation of cellular network is deployed almost every decade [1]. One of the challenges of the upcoming $5 \mathrm{G}$ millimeter-wave network is the realization of backhaul links with high-gain fixed antennas operating in the V- or E-bands. To reduce the visual impact of such antennas in urban areas, the use of low-profile architectures is mandatory. High gain antennas operating over a large band are also mandatory to sustain the required data rate and at the same consitime overcome the free space attenuation at such frequency range. The possibility to reconfigure the

The research leading to some of these results has received funding from the European Union Seventh Framework Programme (FP7/2007-2013) under grant agreement no. 619563 (MiWaveS).

T. Potelon, M. Ettorre, Laurent Le Coq and R. Sauleau are with the Institut d'Electronique et de Télécommunications of Rennes (IETR), UMR CNRS radiation patterns over a small angular range $\left( \pm 10^{\circ}\right)$ is also necessary to facilitate the operation of alignment during installation or to allow self-alignment during operation.

All these features make the design challenging, especially at millimeter-wave frequencies. Most of the common high-gain antenna architectures do not fulfill these requirements. Serialfed arrays [2] and travelling-wave antennas [3] suffer either from a limited bandwidth or a dispersive behavior. Above 30 $\mathrm{GHz}$, the losses of the beam-forming network of parallel-fed patch arrays become critical and lead to efficiencies in the order of $20 \%$ [4]. Resonant cavities excited by a hollow corporate feed network provide a high gain and a broadband operation with a low profile, but they do not present any beam steering capability [5]. In contrast, aperture antennas such as reflector [6] and lens antennas [7] (and the more recent reflectarrays and transmittarrays [8], [9]) are particularly adapted for beam steering but their focal length makes them inherently bulky.

Recently we investigated the suitability of Continuous Transverse Stub (CTS) antennas at millimeter-waves for 5G applications, e.g. [10]. The radiating part of CTS antennas is a set of long radiating slots closely arranged side by side in a onedimension array. These slots are realized by vertical openended PPWs supporting the transverse electromagnetic (TEM) mode. These radiating elements are non-resonant, and therefore their behavior is almost independent of frequency, especially when fed in parallel by a true-time delay network in PPW technology. The TEM mode needed to feed this corporate feed network is generally provided by a pillbox system [11] consisting of two stacked PPWs connected by a parabolic reflector and a multi-slot coupler [12]. A focal horn placed in the focal plane of the parabolic reflector generates the required TEM mode. Moreover, displaced horns in the focal plane of the parabolic reflector allows steering of the antenna beam in $\mathrm{H}$ plane.

Compared to the already existing CTS antennas, the main innovations of the antenna presented in this paper are twofold: a) The use of advanced PCB fabrication technology for cost and

6164, Université de Rennes 1, 35042 Rennes, France (e-mail: thomas.potelon@univ-rennes1.fr).

T. Bateman and J. Francey are with Optiprint AG, Auerstrasse 37, CH-9442 Berneck, Switzerland (e-mail: t.bateman@optiprint.co.uk, j.francey@optiprint.co.uk). 
size reduction suitable for systems in-package. Most of the high-gain CTS antennas use computer numerically control milling machines [10], [13] or LTCC substrates [14];

b) The design of a new feeding system offering, for the first time, beam reconfiguration in both principal radiating planes of the array.

In [10] we demonstrated the relevance of CTS architectures for millimeter-wave high gain applications: the designed antenna was able to produce a very stable gain higher than 29.3 $\mathrm{dBi}$ over the full E-band $(71-86 \mathrm{GHz})$. However the fabrication procedure included the combination of two technologies: milling of aluminum pieces and printed circuit board (PCB) technology. Therefore, a specific transition with chamfered PCB was necessary, and the complex mechanical assembly made the antenna expensive and difficult to integrate. In [16], the authors developed a new planar technology to build parallelfed CTS antennas, but the use of conductive adhesive layers and air cavities led to a very complex and expensive stack-up comprising more than 20 layers. In [14], a CTS antenna was fabricated exclusively in low-temperature co-fired ceramic (LTCC) technology to reduce the cost and complexity of fabrication and to facilitate its integration. This design used substrate integrated PPWs (SI-PPWs) [14] which allow the implementation of vertical PPWs using only metalized vias. Nonetheless, the main issue with the selected fabrication technology is the high permittivity of ceramic substrates which is far from ideal for antenna designs. For this reason, only four slots were implemented resulting in a broad beam in E-plane. SI-PPW technology is selected for its good performance [14]. However, in contrast to LTCC technology, the main challenge with organic substrates is to overcome the absence of physical contact between metallic layers of different substrates, which can cause important leakages and lead to major performance degradations of the system. Such a physical contact is here replaced by a capacitive coupling avoiding buried vias within the stack up.

Scanning capability in H-plane has been reported for parallel-fed CTS arrays. To the authors' knowledge, no parallel-fed CTS antenna described in the open literature is able to offer a radiation pattern reconfigurability in E-plane. This lack of versatility makes the alignment difficult for point-topoint communications. The antenna system proposed in this paper is based on a novel architecture able to generate either a sum or a difference pattern in E-plane. This architecture is based on the combination of two quasi-optical systems feeding the CTS array. Besides providing the sum and difference patterns, such an architecture allows steering the radiation pattern in $\mathrm{H}$ plane to a fully agility of the antenna.

The paper is organized as follows. The antenna architecture and its operation are presented in Section II. The technological solutions adopted for PCB fabrication are described in Section III. Then the design of each building block, according to the fabrication constraints, is detailed in Section IV. Measurements are compared to simulations in Section V. Conclusions are drawn in Section VI.

\section{Presentation of the antenna ARChitecture}

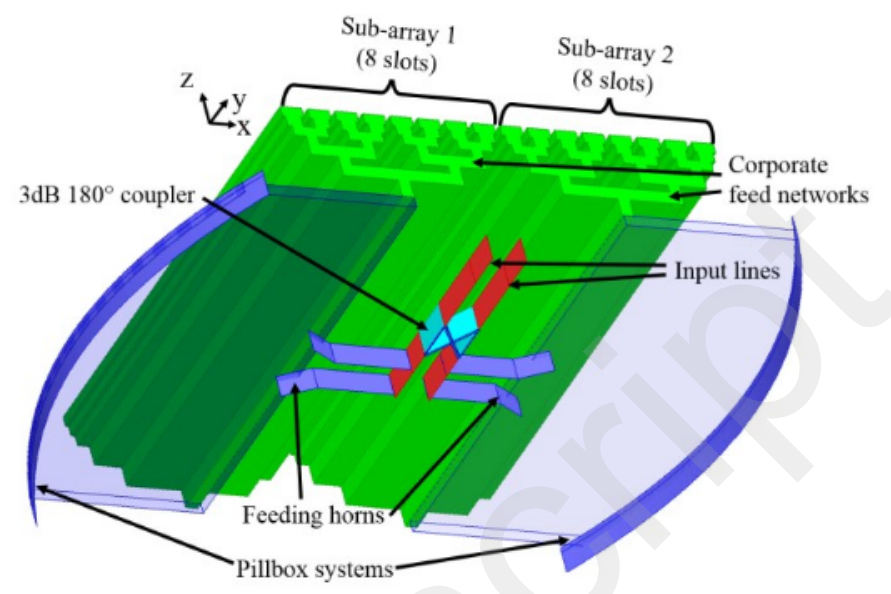

Fig. 1. Overview of the antenna architecture from the bottom.

The antenna system is depicted in Fig. 1. The radiating part is a 16-slot CTS-array fed in parallel. It is dived into two subarrays of 8 slots each, fed by separated corporate feed networks in PPW technology. Two pillbox systems are placed back-toback to excite these two sub-arrays. Two integrated feed horns, placed in the focal planes of the pillbox systems, are used to illuminate the parabolic reflectors of the pillbox couplers; they are fed by a $3 \mathrm{~dB}$ coupler. The excitation of the two sub-arrays either in-phase or out-of-phase allows the generation of a sum or a difference pattern in E-plane (i.e. $z x$ plane), respectively. Besides, the generated patterns can be steered in H-plane (i.e. $z y$ plane) by placing several horn in the focal plane of the pillbox systems. Such an architecture provides a reconfigurable pattern simultaneously in E- and $\mathrm{H}$-planes. The phase difference between the sub-arrays is controlled by the $180^{\circ} 3$ $\mathrm{dB}$ coupler exciting two pillbox systems. Note that since the pillbox systems are facing one to the other, a $180^{\circ}$ phase shift is naturally introduced; therefore exciting them in-phase generates the difference pattern and exciting them out-of-phase generates the sum pattern.

\section{ANTENNA TECHNOLOGY}

\section{A. Printed circuit board (PCB) fabrication}

The proposed proof-of-concept, with a lower gain compared to standard values for point-to-point communications in Eband, is entirely fabricated in PCB technology. The $3 \mathrm{~dB} 180^{\circ}$ coupler and the pillbox systems can be fabricated in standard SIW technology [3], however the corporate feed network and the radiating slots require the implementation of horizontal (parallel to the $x y$-plane in Fig.1) and vertical PPWs (orthogonal to the $x y$-plane in Fig.1) within the stack-up. Horizontal PPWs can be realized with the substrate metallization. On the other hand, via-made vertical PPWs are implemented using SI-PPW technology [14] as detailed in Section III.B.

A large number of buried vias would be necessary to obtain a connection between the via walls and the copper layers (i.e. between the vertical and horizontal PPWs). Such vias will be extremely challenging for fabrication, or even impossible to 
fabricate, and would increase drastically the final cost of the antenna while spoiling its reliability. The employed fabrication procedure is instead presented in Section III.C.

Considering the large number of substrate layers (12 layers here, see Section IV), it is preferable to use the same substrate material and height for every layer to minimize the thermal and mechanical constraints and improve the reliability of the entire fabrication procedure. The selected substrate is Rogers ULTRALAM 3850 of $0.175 \mathrm{~mm}$ thickness $\left(\varepsilon_{\mathrm{r}}=3.1\right.$ and $\tan \delta=0.004$ at $78.5 \mathrm{GHz}$ according to private conversations with the provider), and the adhesive layer used for lamination is Rogers CuClad $6250\left(\varepsilon_{\mathrm{r}}=2.32\right.$ and $\tan \delta \approx 0.003$ at $\left.78.5 \mathrm{GHz}\right)$. The copper thickness of each metallic layer of the stack up is estimated to $25 \mu \mathrm{m}$. According to [15], the effective conductivity of copper can be calculated using the following formula: $\sigma_{\text {eff }}=58 \times 10^{6} \times \mathrm{e}^{-0.0192 \mathrm{f}} \mathrm{S} . \mathrm{m}^{-1}$, where $f$ is the frequency in $\mathrm{GHz}$. At the central frequency, the effective conductivity of copper is $1.3 \times 10^{7} \mathrm{~S} . \mathrm{m}^{-1}$. These values are used for all simulation results provided in this paper.

\section{B. SI-PPW in PCB technology}

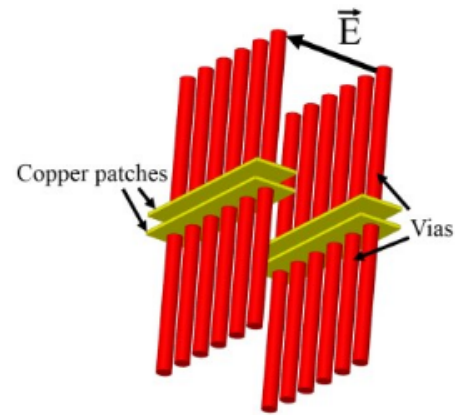

(a)

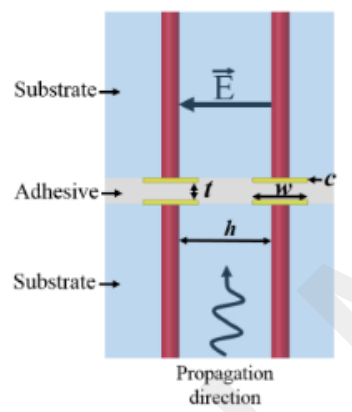

(b)
Fig. 2. Contactless SI-PPW in PCB technology: perspective view (a) and cross sectional view (b).

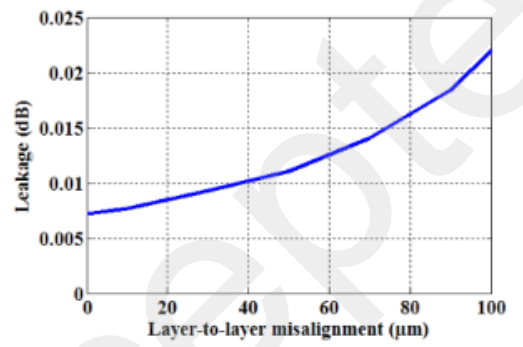

Fig. 3. Leakage loss as a function of the layer-to-layer misalignment.

The issue of the absence of continuous vertical walls have already been addressed in [14] where SI-PPWs were first introduced in LTCC technology. An advanced analysis concluded that the replacement of the parallel plates by rows of vias only induces a very slight increase of ohmic loss without affecting the guidance of the TEM mode.

LTCC technology does not require bonding layers and buried vias can be employed. However, in PCB technology, the adhesive layers prevent from a physical contact between the metallization of different substrate layers. Since buried vias are not a viable solution in terms of cost, complexity and reliability, we recently developed a contactless technique [17]. This new solution, shown in Fig. 2, relies on in using metallic strips over both sides of the via rows on the two separate substrates. Such strips create a capacitive coupling between the two substrates allowing vertical propagation of the TEM mode through the bonding film. Geometrical details of the transition, depicted in Fig. 2 were selected as follows:

- The thickness $t$ of the bonding layer between the coupling patches, and the thickness $c$ of the copper layers are linked to the selected fabrication technology and processes.

- Most of the insertion losses are ohmic (in the metal) [14], and they can be reduced by increasing the PPW height $h . h$ is then set as large as possible, while providing a good impedance matching and mono-modal propagation.

- Larger capacitive widths $w$ (greater than $0.25 \mathrm{~mm}$ ) make the waveguide transition more stable against layer-to-layer misalignment whereas a smaller width (less than $0.2 \mathrm{~mm}$ ) improves the transition matching with a perfect layer-tolayer alignment. In this work, $0.3 \mathrm{~mm}$ wide strips were selected to insure a robustness against layer-to-layer misalignments up to $50 \mu \mathrm{m}$.

The final geometrical parameters are the following: $c=25$ $\mu \mathrm{m}, h=0.5 \mathrm{~mm}, t=10 \mu \mathrm{m}, w=0.3 \mathrm{~mm}$. Moreover the vias have a diameter and a periodicity of $0.1 \mathrm{~mm}$ and $0.2 \mathrm{~mm}$, respectively. The leakage loss per transition (between the capacitive lines) is then computed with Ansys HFSS 16.0 as a function of the layerto-layer misalignment; it is represented in Fig. 3 at an operating frequency of $78.5 \mathrm{GHz}$. This figure shows that it remains lower than $0.03 \mathrm{~dB}$ even for the very unlikely case of a $100 \mu \mathrm{m}$ misalignment. These results do not change in the band 71-86 $\mathrm{GHz}$. This contact-less transition is key for the implementation of broad-band vertical PPW waveguides in PCB technology. Besides, it enables the design of complex 3D architectures, such as parallel-fed CTS antennas, without any need for electrical contact between layers.

\section{Fabrication steps}

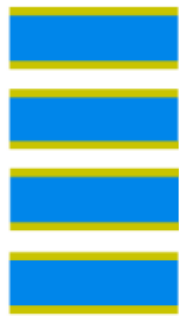

(a)

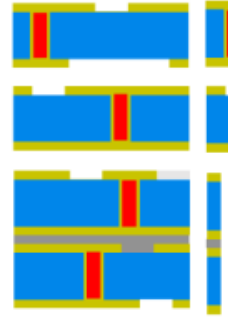

(e)

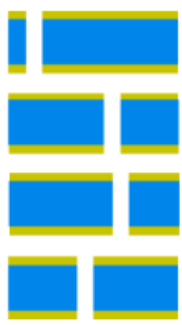

(b)

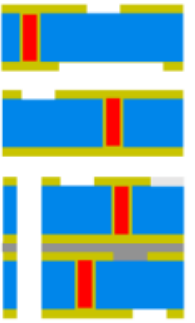

(f)

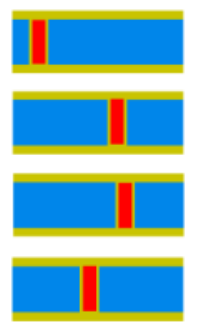

(c)

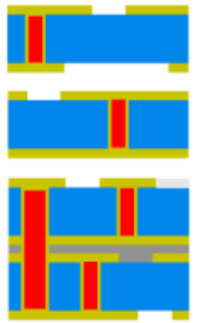

(g)

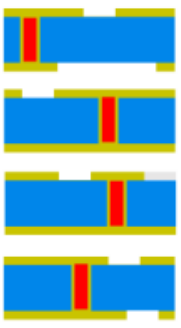

(d)

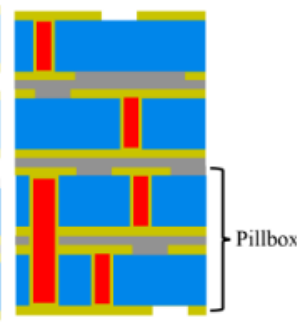

(h)
Substrate Resin Copper D Dhesive Fig. 4. Fabrication steps: initial metalized substrates (a), drilling (b), plating and resin filling of the vias (c), chemical etching (d), bonding of the two lower substrates (e), drilling through the two lower substrates (f), plating and resin filling of the vias ( $\mathrm{g})$, and bonding of all layers $(\mathrm{h})$. 


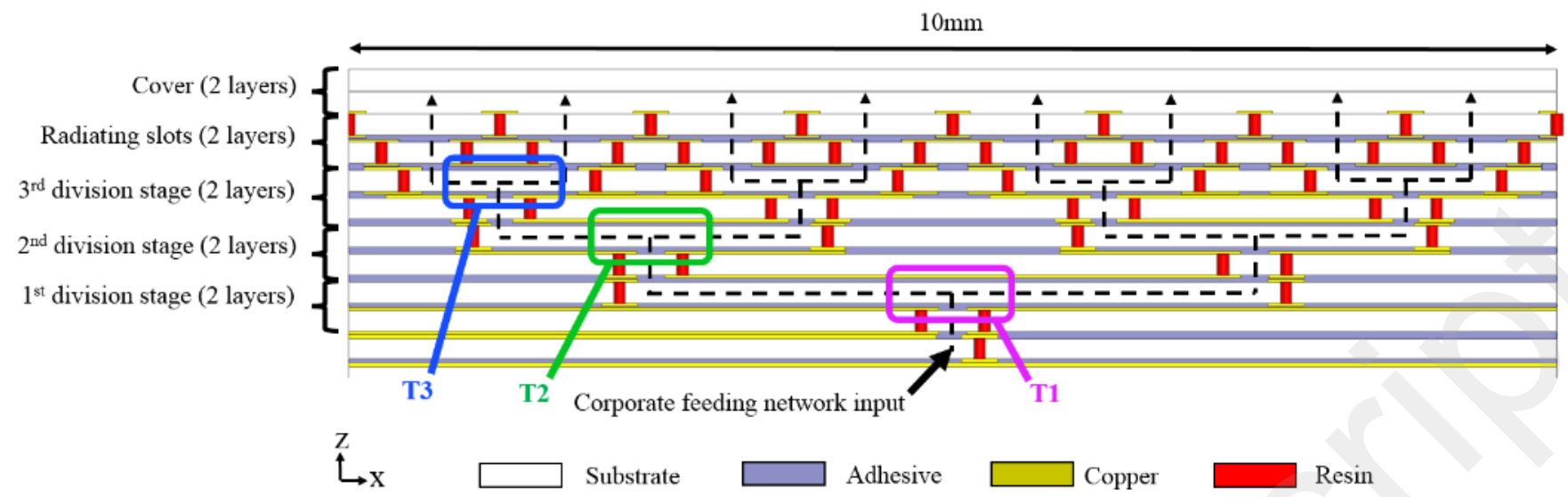

Fig. 5. Cross-sectional view of a sub-array and its SI-PPW corporate feed network. T1, T2 and T3 are power dividers used in the various stages.

Contactless SI-PPW transitions do not require buried vias. A simple fabrication procedure based on a single bonding phase can be thus employed for the corporate feed network. Such a procedure is composed of several steps, as illustrated in Fig. 4. First, the copper-plated substrate layers are drilled and the resulting holes are metallized and filled with resins. Then the copper layers are chemically etched according to the desired patterns. Finally, all modules are assembled with dielectric adhesive layers in a single bonding process. The thickness of the bonding layers is estimated smaller than $10 \mu \mathrm{m}$. The benefit of this procedure relies on its simplicity regardless of the number of stacked substrate layers.

This assembling procedure cannot be applied to the pillbox systems since the vias composing the parabolic reflector should go through two substrate layers to avoid leakage. For this reason, a slightly different procedure is employed for such transition, as graphically described in Fig. $4 \mathrm{~g}$ and $4 \mathrm{~h}$. In detail, the metallized through vias of the feeding horns $(0.1 \mathrm{~mm}$ diameter with a pitch of $0.2 \mathrm{~mm}$ ) and the copper etching are realized. The two bottom substrate layers used for the pillbox systems are then assembled, and the vias forming the reflectors are drilled through both substrates and metallized $(0.35 \mathrm{~mm}$ diameter on a $0.5 \mathrm{~mm}$ pitch), thus avoiding leakage in the glue layer. Then a second bonding step is necessary to assemble the rest of the stack-up to finalize the structure. The fabrication accuracy of the metalized via holes and the copper plating is about $10 \mu \mathrm{m}$. The maximum shift between two adjacent layers is lower than $50 \mu \mathrm{m}$.

\section{ANTENNA DESIGN}

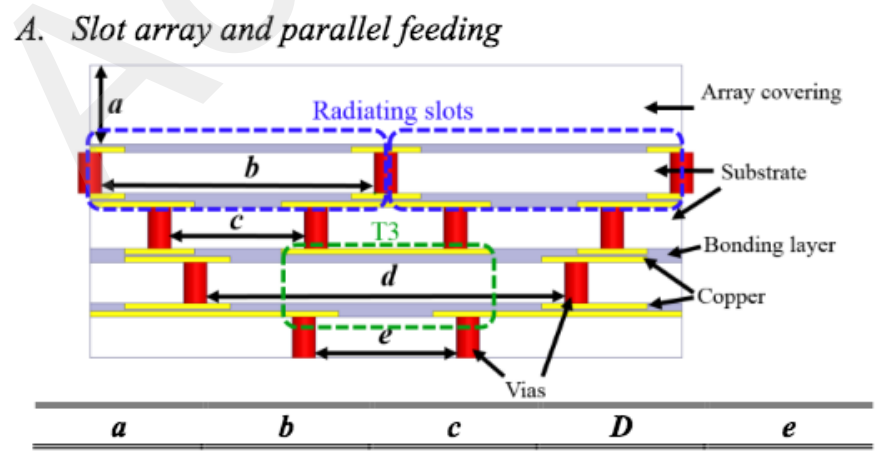

\begin{tabular}{lllll}
\hline \hline $0.35 \mathrm{~mm}$ & $1.17 \mathrm{~mm}$ & $0.57 \mathrm{~mm}$ & $1.53 \mathrm{~mm}$ & $0.60 \mathrm{~mm}$ \\
\hline
\end{tabular}

Fig. 6. Geometry and dimensions of the radiating slots fed by junction T3 (only two radiating slots are shown here). The array covering is made of two substrate layers (see Fig. 5).

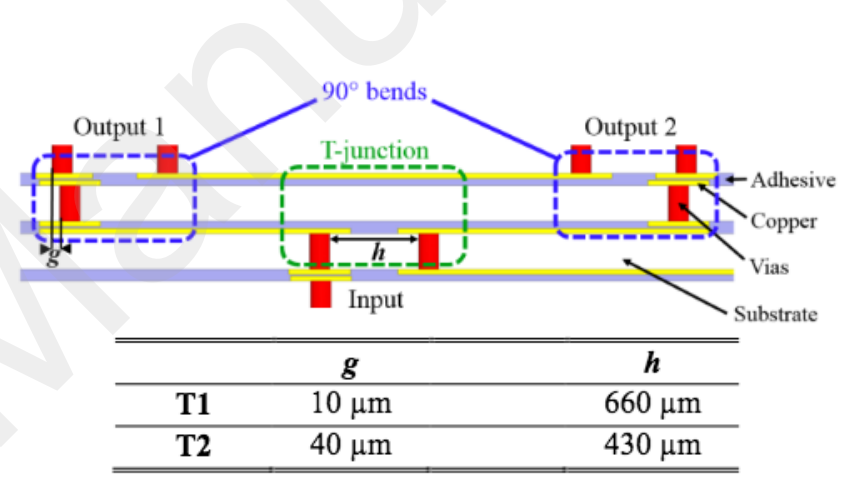

Fig. 7. Geometry and dimensions of the second power division stage, including the $\mathrm{T} 2$ junction followed by two right-angle bends.

A cross-sectional view of a part of the 8-slot sub-array and its parallel feeding is presented in Fig. 5. They have been designed using full-wave simulations using Ansoft HFSS version 16.0.0. The two upper substrates are introduced for matching purposes [18]. The size of the array was a tradeoff between high gain and layer-to-layer misalignments. However, considering the quality of the measured results, the same concept could be extended to an array at least four times larger. The periodicity of the slot array is set to half wavelength at 78.5 $\mathrm{GHz}$ to maximize the gain while preventing the appearance of grating lobes.

The slots are excited by the T-junctions $\mathrm{T} 3$. The array active impedance [18] is matched at the input port of T3. Such a solution is preferred to match the active impedance at the slot level for a reduced complexity of the design. The geometry and dimensions of the slots fed by T3 junctions are provided in Fig. 6. In the simulation, the last division stage loaded by the slot array is matched below $-22.5 \mathrm{~dB}$ and the insertion loss is negligible $(<0.1 \mathrm{~dB})$.

The first and second power divisions in the corporate feed network are realized by the $\mathrm{T}$-junctions $\mathrm{T} 1$ and $\mathrm{T} 2$, respectively, and their geometry is presented in Fig. 7. Both $\mathrm{T} 1$ and $\mathrm{T} 2$ share the same geometry and their unique degree of freedom for 
matching is their input PPW height $h$. The position $g$ of the viawalls forming the right-angle bends is a sensitive variable: a 50 $\mu \mathrm{m}$ shift implies $0.45 \mathrm{~dB}$ of additional loss. This variable can be also tuned to improve the impedance matching (see Fig. 7).

Ten substrate layers are used in total for the corporate feed network and the slot array. The final slot array, containing the two sub-arrays, has a total length of $20 \mathrm{~mm}$ (see Fig. 5).

The simulated insertion loss through the entire corporate feed network is between $0.6 \mathrm{~dB}$ and $0.95 \mathrm{~dB}$ for the $71-86 \mathrm{GHz}$ band. The input reflection coefficient is lower than $-18 \mathrm{~dB}$. The simulated radiation efficiency is thus equal to $80-87 \%$ (for the slot array and the corporate feed network only).

\section{B. Pillbox systems}

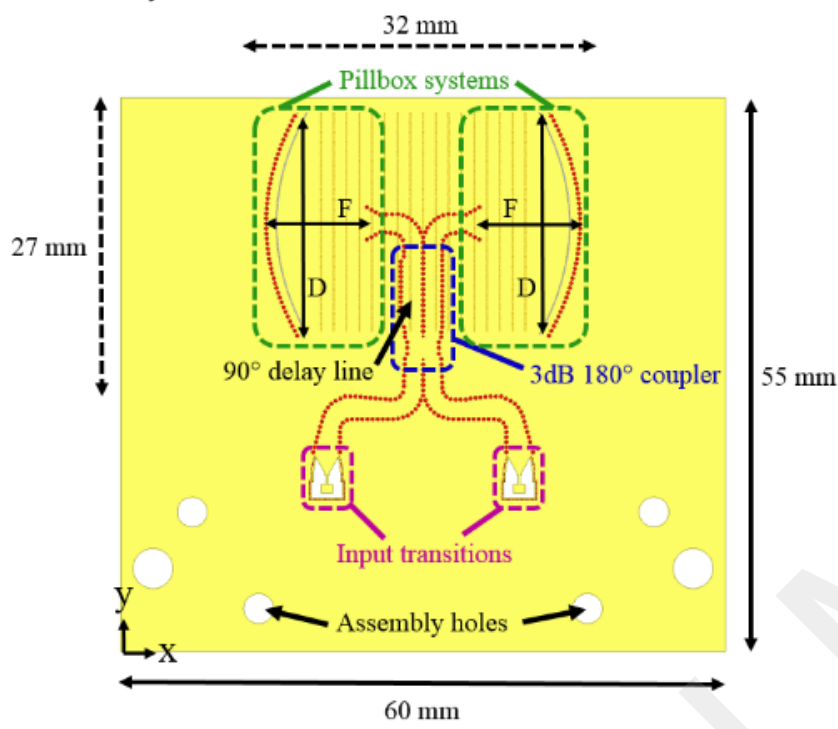

Fig. 8. Bottom view of the antenna. The pillbox systems, $3 \mathrm{~dB} 180^{\circ}$ coupler and the input transitions can be recognized. The entire module dimension (solid arrows) and the antenna dimensions without the input transitions (dash arrows) are provided. $F$ and $D$ stand for the focal length and the diameter of the parabolic reflectors, respectively.

The two pillbox systems, presented in Fig. 8, are implemented on two substrate layers at the bottom of the antenna stack-up, as represented in Figs. 4 and 5. They are identical and they excite the two sub-arrays (through a simple PPW $90^{\circ}$ bend) with the same amplitude and phase distribution. Their focal length is set to $10 \mathrm{~mm}$ to match the slot array area for compactness.

The dimensioning of the pillbox system mainly follows the guidelines provided in [9]. The design procedure is composed of 4 steps.

- The first step is to derive the parabola diameter and the feeding horn width from a ray-tracing tool presented in [9], as a tradeoff between the beam width, the side lobe level and the overall size of the system. The final system has an $F / D$ ratio of 0.45 (see Fig. 8) and an edge taper level lower than $-20 \mathrm{~dB}$. It is worth noting that such a small F/D value is considered sufficient for the required scanning.

- The second step is the design of the multi-slot coupler at the center of the parabola for normal incidence, as detailed in [3].

- The third step is the derivation of the coupler dimensions along the parabola from its dimensions at the center, using the procedure also described in [3].

- Finally a full-wave model of the entire pillbox system, using exclusively via-made walls, is simulated for validation.

The steering capability in H-plane is achieved by displacing the two feed horns in the focal planes of the parabolas. We have designed two antennas, named in the following "Configuration 1 " and "Configuration 2" with the same radiating part as described above to validate such a steering capability. In Configuration 1, the two pillbox systems are fed by a horn placed at the focus of the pillbox system, whereas for Configuration 2, the feeding horn is shifted by $1.65 \mathrm{~mm}(0.75$ $\lambda_{\mathrm{d}}$, with $\lambda_{\mathrm{d}}$ the wavelength within the substrate at $78.5 \mathrm{GHz}$ ) along the focal plane. They generate a beam pointing at $0^{\circ}$ and $-14^{\circ}$ in H-plane, respectively.

Across the operating band, the simulated reflection coefficients are lower than $-15 \mathrm{~dB}$ and $-18 \mathrm{~dB}$ for configuration 1 and configuration 2, respectively; the simulated insertion loss is identical for both configurations and is about $2.3 \mathrm{~dB}$ at $78.5 \mathrm{GHz}$.

\section{C. $3 \mathrm{~dB} 180^{\circ}$ coupler}

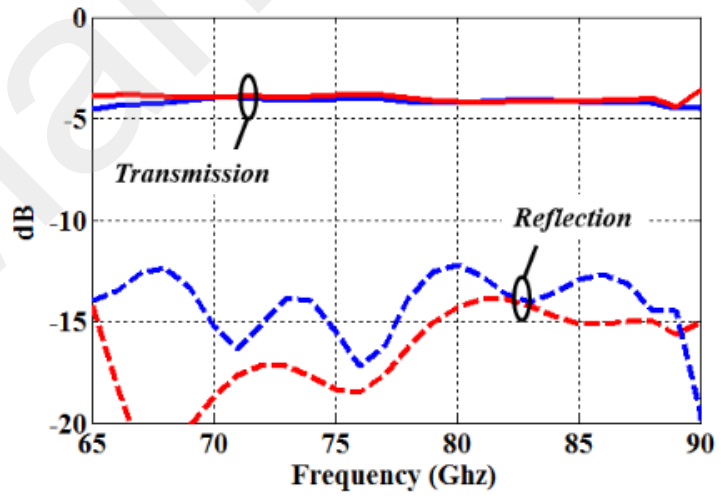

(a)

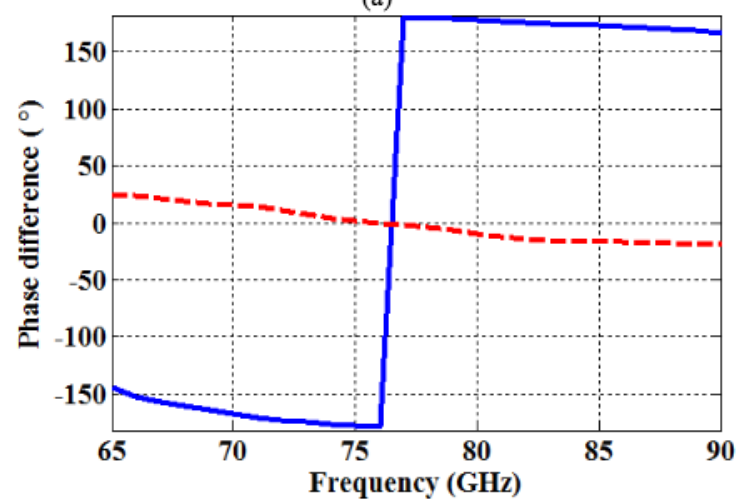

(b)

Fig. 9. $180^{\circ}$ coupler simulated results in the two possible states (depending on the feeding port): amplitude of the transmission and reflection coefficients (a), and phase differences between the two output ports (b).

The $3 \mathrm{~dB} 180^{\circ}$ coupler is shown in Fig. 8. The function of this building block is twofold. First it divides the input power into the two sub-arrays (through the pillbox systems). Secondly it controls their relative phase: exciting them in-phase produces the sum pattern and out-of-phase the difference pattern. It is composed of a $3 \mathrm{~dB} 90^{\circ}$ coupler directly followed by a $90^{\circ}$ delay 
line. This coupler is inspired by [19], and the delay line is implemented by properly tuning the waveguide width. This geometry was selected for its long and narrow shape which fits very well between the two pillbox systems (as shown in Fig. 8), and for its compliance with SIW technology. The simulation results of the coupler are shown in Fig. 9. In the 71-86 GHz band, the maximum amplitude difference observed between the two output ports of the coupler is $0.2 \mathrm{~dB}$ and the maximum phase error is $17^{\circ}$ (corresponding to $\lambda_{g} / 20$ with $\lambda_{g}$ the guided wavelength). The $3 \mathrm{~dB} 180^{\circ}$ coupler is realized in the bottom substrate layer, as shown in Fig. 8.

\section{Input transition}

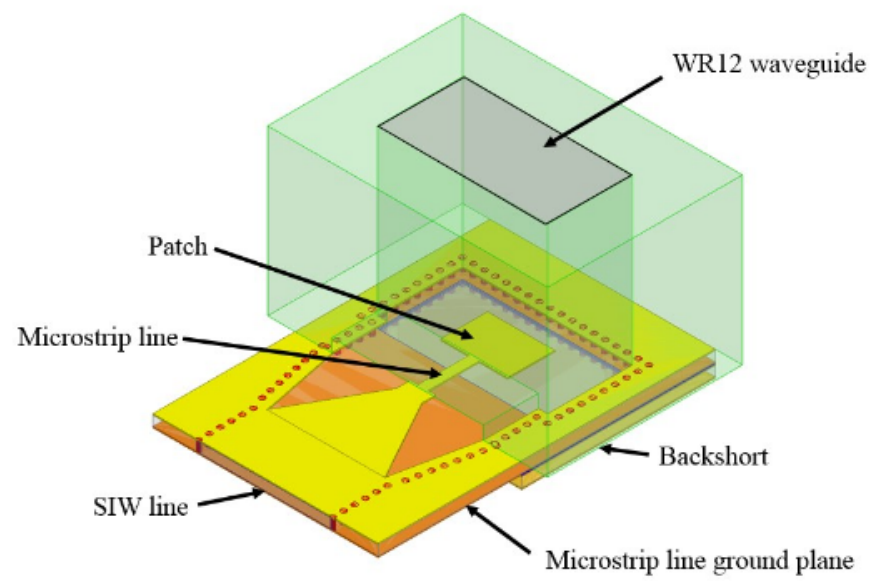

(a)

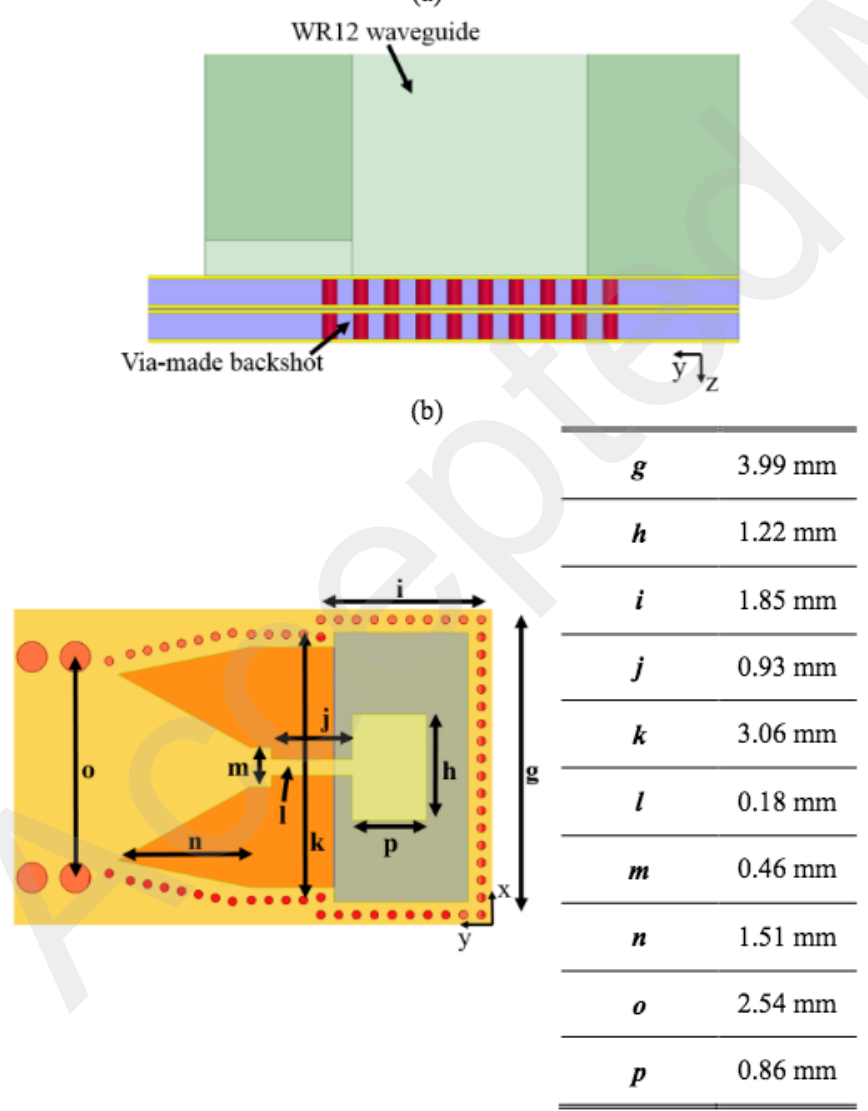

(c)

Fig. 10. Perspective view (a), cross-sectional view (b) and top view with dimensions (c) of the input transition.

For measurement purposes, the antenna is excited by two standard waveguides (WR12), each feeding the coupler by a different input port. One input port generates the sum pattern in E-plane ( $x z$ plane) whereas the other one generates the difference pattern. It is worth saying that such a transition is not necessary for an in-package system.

The transition, depicted in Fig. 10, is composed of a rectangular patch placed into the waveguide and followed by a microstrip-to-SIW transition. Its operation is very similar to the one described in [10]. However, here the waveguide backshort is realized using exclusively metalized via holes. Unlike the standard SIW technology, here the wave propagates vertically along the vias axis direction. Moreover, copper strips induce a capacitive effect to realize a contactless connection between the vias of the different substrate layers, thus mimicking a continuous rectangular waveguide supporting the $\mathrm{TE}_{10}$ mode.

In the simulations, the input reflection coefficient is lower than $-19 \mathrm{~dB}$ in the target band $(71-86 \mathrm{GHz})$ and the insertion loss is between $0.4 \mathrm{~dB}$ and $1.5 \mathrm{~dB}$ for the same frequency band. The simulated leakage loss is negligible. These results are in line with those obtained for a very similar transition using a metallized trench [10]. Thus, the contact-less SI-PPW technology is also relevant for the propagation of a vertically oriented transverse electric modes.
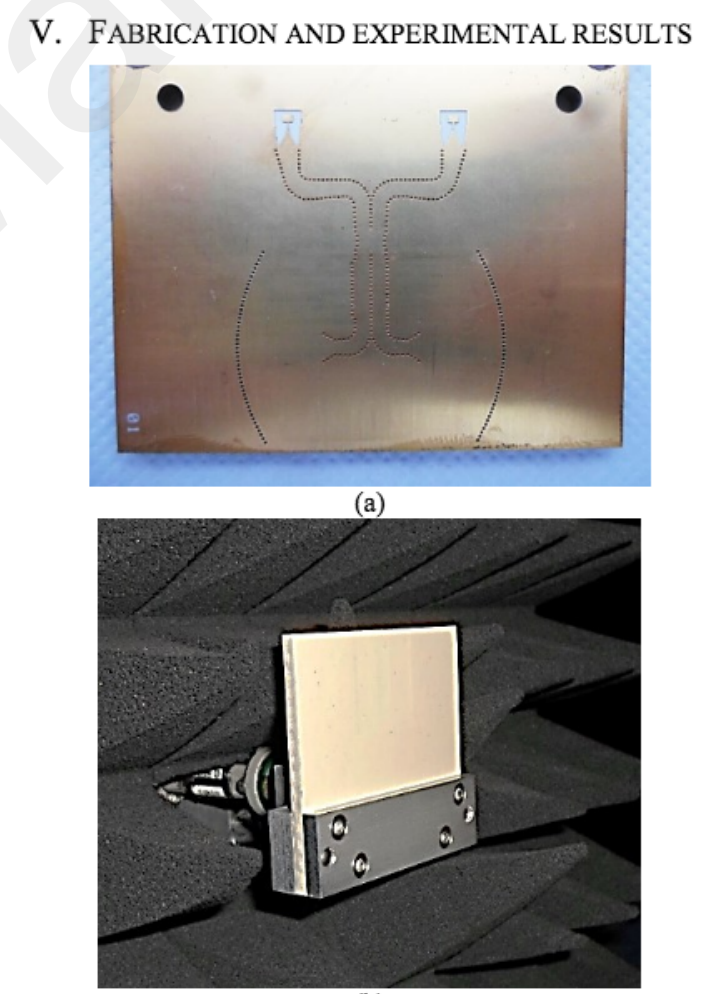

(b)

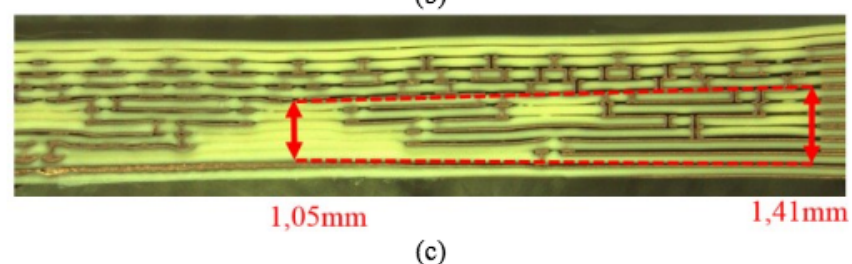

Fig. 11. Pictures of the fabricated prototypes: bottom view (a), antenna in the anechoic chamber (b) and cross-sectional view in the $x z$ plane as in Fig.5 (c). 


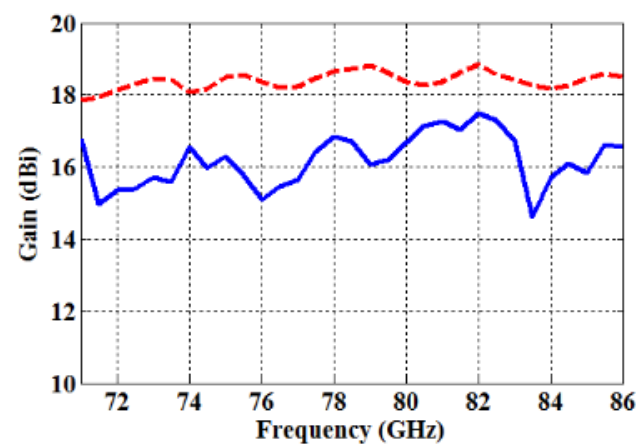

Fig. 12. Measured (solid blue curve) and simulated gain (dash red curve) as a function of frequency.

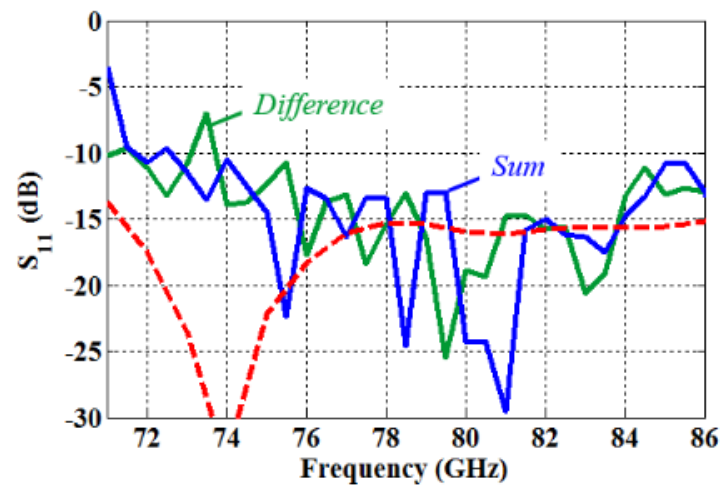

Fig. 13. Measured (solid curves) and simulated (red dash curve) reflection coefficients.

Two prototypes (corresponding to Configurations 1 and 2, see Section IV-B) have been fabricated with the procedure described in Section III.C. The metallic parts used for the feed waveguides are fabricated in aluminum using milling and wirecutting techniques. Pictures of the prototypes are presented in Fig. 11. The entire antenna module, without the input transitions, measures $32 \times 27 \times 2.7 \mathrm{~mm}^{3}$ and comprises more than 12000 metalized vias. After the experimental characterization, one measured prototype (configuration 1) was micro-sectioned along the $x z$-plane (see Fig. 1) to assess the fabrication accuracy of the antenna, as shown in Fig. 11(c). A layer-to-layer misalignment of $58 \mu \mathrm{m}$ was measured between the two lower substrates (containing the pillbox systems) and the rest of the antenna. The maximum layer-to-layer misalignment measured at the corporate feeding network level was only $20 \mu \mathrm{m}$. Such a level of misalignment does not impact the radiation patterns as clearly shown by the measured patterns (shown in Fig. 14 and Fig. 15) The misalignment has also a limited impact in the loss increase (in the $0.5 \mathrm{~dB}$ range). A significant shrinking of the module at the center of the antenna was also observed, as clearly seen in Fig. 11(c). The measured thickness of the stack-up is $1.05 \mathrm{~mm}$ at the center of the antenna and $1.41 \mathrm{~mm}$ at the edges. The most likely explanation for this difference in thickness is the absence of metal in the central area between the two corporate feeding networks. This effect could be easily prevented by simply not etching the copper in this area.

Fig. 12 compares the measured and simulated realized gains as a function of frequency. The measured gain variation is lower than $3 \mathrm{~dB}$ over the entire E-band, and the maximum gain reaches $17.5 \mathrm{dBi}$. This corresponds to an antenna efficiency of $18 \%$ (against $28 \%$ in simulation). The value of the experimental loss is approximately $2 \mathrm{~dB}$ higher than in the simulations. About $1.2 \mathrm{~dB}$ out of it is attributed to the shrinking of the middle part of the antenna, and $0.5 \mathrm{~dB}$ is caused by the layer-to-layer misalignment (according to a posteriori simulations based on the prototype micro-section measurements). The remaining difference can be attributed to the copper surface roughness. Table 1 summarizes the overall antenna loss at the center frequency of $78.5 \mathrm{GHz}$.

Table 1: Antenna complete power budget at $78.5 \mathrm{GHz}$

\begin{tabular}{cc}
\hline Simulated directivity & $24.0 \mathrm{dBi}$ \\
\hline Metal and dielectric losses & $5.3 \mathrm{~dB}$ \\
\hline Antenna middle part shrinking & $1.2 \mathrm{~dB}$ \\
\hline Layer-to-layer misalignments & $0.5 \mathrm{~dB}$ \\
\hline Calculated gain & $17.0 \mathrm{dBi}$ \\
\hline Measured gain & $16.7 \mathrm{dBi}$ \\
\hline \hline
\end{tabular}

The simulated and measured radiation patterns in $\mathrm{H}$-plane are presented in Fig. 15. A good agreement is achieved for both configurations 1 (beam pointing at $\left.0^{\circ}\right)$ and $2\left(14^{\circ}\right.$ beam steering), although the SLL for configuration 2 is higher than expected around $71 \mathrm{GHz}$, which is mostly attributed to leakage on the side of the pillbox system.

The radiation patterns measured in E-plane are compared to the simulations in Fig. 14. The presented results were obtained for configuration 1, although configuration 2 provided the same patterns in E-plane. Despite the slight asymmetry of the side lobes observed at lower frequencies, the sum pattern is wellshaped and in good agreement with simulations. The difference patterns are properly generated, especially from 76 to $86 \mathrm{GHz}$ where the lobe difference is lower than $1 \mathrm{~dB}$. The null is wellcentered at $0^{\circ}$ with a depth of more than $-23 \mathrm{~dB}$. These sum and difference radiation patterns remain perfectly identical when steered in H-plane.

The antenna input reflection coefficients are presented in Fig. 13 for the sum and difference ports. The antenna is matched below $-10 \mathrm{~dB}$ from $74 \mathrm{GHz}$ to $86 \mathrm{GHz}$.

The measurement results fully validate the proposed architecture and fabrication process.

\section{CONCLUSION}

A low-profile CTS antenna has been designed in E-band for backhaul applications for next generation 5G networks. Standard PCB processes have been adopted for cost reduction and easy integration. The novel architecture consists of two sub-arrays of 8 slots each fed by two quasi-optical systems. The antenna system can generate sum and difference patterns along the E-plane with a scanning capability along the H-plane. To the best of our knowledge this 2-plane reconfigurability has never been applied to parallel-fed CTS antennas in the open literature. Such a solution will facilitate the alignment operation during the installation of backhaul antennas.

Two prototypes were fabricated and characterized. The measured radiation patterns are in very good agreement with simulations in the $71-86 \mathrm{GHz}$ band. The peak gain is $17.5 \mathrm{dBi}$, 


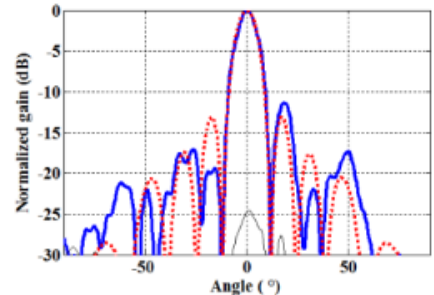

(a)

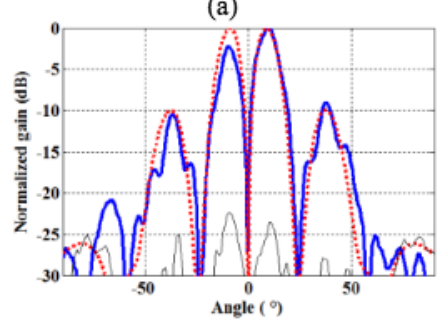

(e)

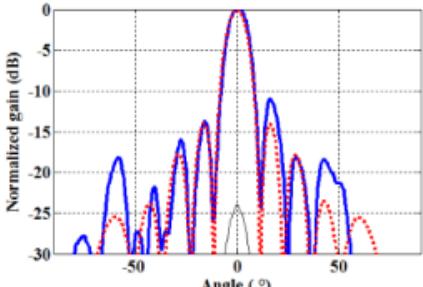

(b)

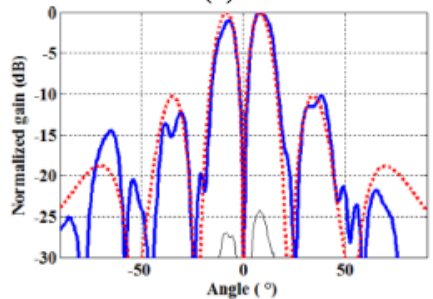

(f)

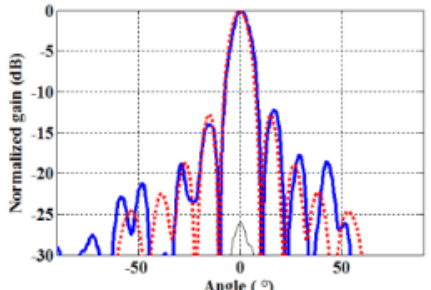

(c)

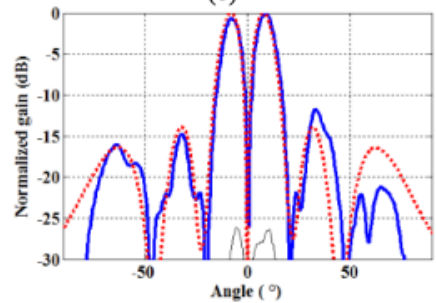

(g)

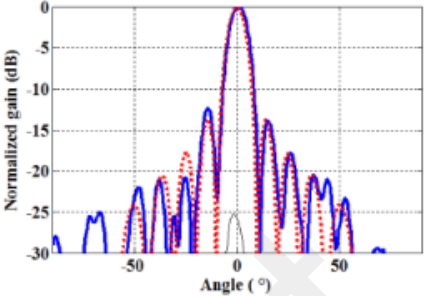

(d)

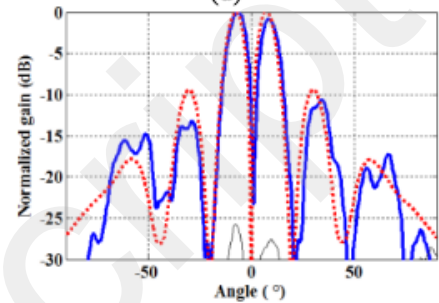

(h)

Fig. 14. Comparison between the measured (blue solid curves) and simulated (red dotted curves) radiation patterns in E-plane for configuration 1, for the sum (a)-(d) and difference (e)-(h) patterns, respectively, at $71 \mathrm{GHz}(\mathrm{a}),(\mathrm{e}), 76 \mathrm{GHz}(\mathrm{b}),(\mathrm{f}), 81 \mathrm{GHz}(\mathrm{c}),(\mathrm{g})$ and $86 \mathrm{GHz}(\mathrm{d}),(\mathrm{h})$.

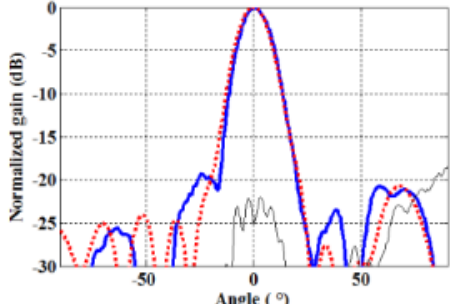

(a)

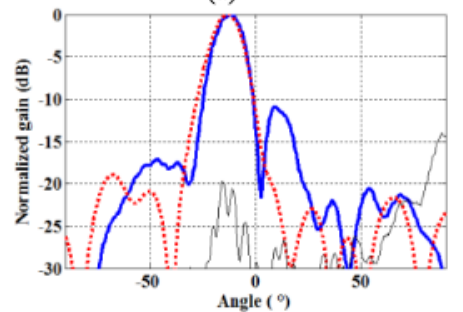

(e)

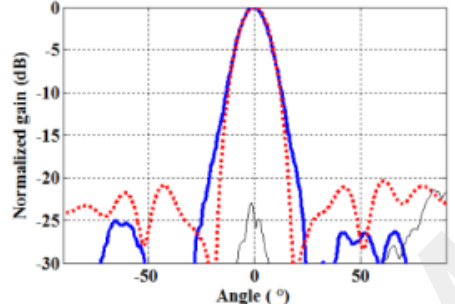

(b)

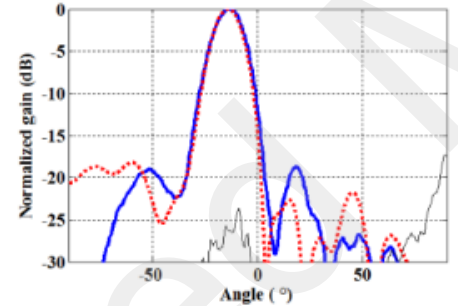

(f)

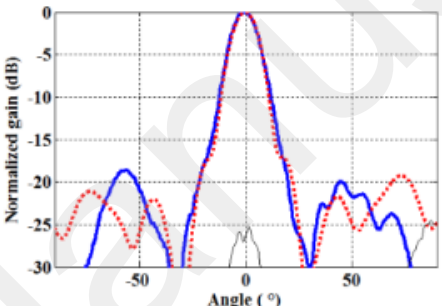

(c)

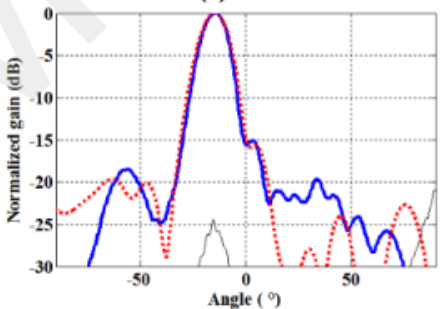

(g)

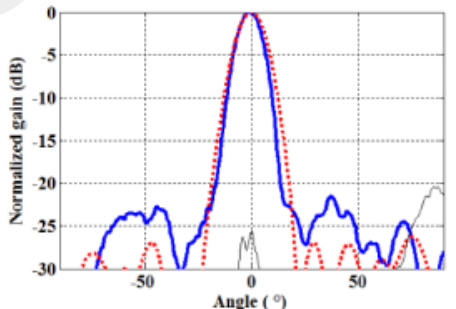

(d)

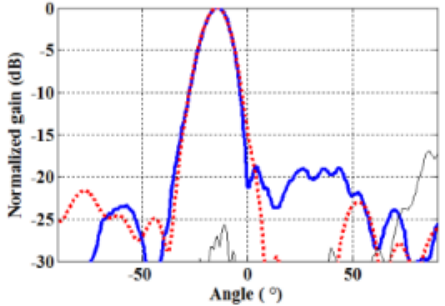

(h)

Fig. 15. Comparison between the measured (blue solid curves) and simulated (red dotted curves) radiation patterns in $\mathrm{H}$-plane for configuration 1 (a)-(d) and 2 (e)(h), respectively, at $71 \mathrm{GHz}(\mathrm{a}),(\mathrm{b}), 76 \mathrm{GHz}(\mathrm{b}),(\mathrm{f}), 81 \mathrm{GHz}(\mathrm{c}),(\mathrm{g})$, and $86 \mathrm{GHz}$ (d), (h).

and its variation is lower than $3 \mathrm{~dB}$. These experimental results demonstrate the reliability of the proposed antenna concept and fabrication technologies. For $5 \mathrm{G}$ backhaul application, this antenna solution can be further extended to a 32 slot array (only 2 additional substrate layers are required) in order to achieve a directivity higher than $30 \mathrm{dBi}$. A new approach allowing the implementation of a CTS antenna with standard, low-cost printed circuit board (PCB) fabrication processes is also reported here. The electrical contact between various stages of the antenna stack-up is achieved with a contact-less technique [17]. Regardless of the antenna size, very few fabrication steps are required to manufacture the separated layers and no more than two bonding phases are required to assemble them.

The proposed antenna presents an interesting tradeoff between high directivity, broad bandwidth, reconfigurability, compactness and low cost which can be very attractive for other applications such as radar detection or the user segment in satellite communications.

\section{REFERENCES}

[1] S. Mattisson, "Overview of $5 \mathrm{G}$ requirements and future wireless networks," $43^{\text {rd }}$ IEEE European Solid State Circuits Conference, Leuven, Belgium, 2017.

[2] M. Zhang, J. Hirokawa, and M. Ando, "A four-corner-fed double-layer waveguide slot array with low sidelobes developed for a $40 \mathrm{GHz}$-band DDD system," IEEE Trans. Antennas and Propag., vol. 64, no. 59, pp. 2005-2010, Mar. 2016.

[3] M. Ettorre, R. Sauleau, and L. Le Coq, "Multi-beam multi-layer leakywave SIW pillbox antenna for millimeter-wave applications," IEEE Trans. Antennas and Propag., vol. 59, no. 4, pp. 1093-1100, Apr. 2011.

[4] Y. J. Cheng, Y. X. Gui, and Z. G. Liu, "W-band large-scale high-gain planar integrated antenna array," IEEE Trans. Antennas and Propag., vol. 62, no. 6, pp. 3370-3373, Jun. 2014.

[5] D. Kim, J. Hirokawa, M. Ando, J. Takeuchi, and A. Hirata, "64×64element and $32 \times 32$-element slot array antennas using double-layer hollow-waveguide corporate-feed in the $120 \mathrm{GHz}$ band," IEEE Trans. Antennas and Propag., vol. 62, no. 3, pp. 1507-1512, Mar. 2014.

[6] P. Zheng, G. Q. Zhao, S. H. Xu, F. Yang, and H. J. Sun, "Design of a Wband full-polarization monopulse cassegrain antenna," IEEE Antennas and Wireless. Propag. Lett., vol. 16, 2016.

[7] "Aperture antennas for millimeter and sub-millimeter wave applications", Eds. A. V. Boriskin and R. Sauleau, Springer, Sep. 2017. 
[8] A. Clemente, L. Dussopt, R. Sauleau, P. Potier, and P. Pouliguen, "Wideband 400-element electronically reconfigurable transmitarray in X band," IEEE Trans. Antennas and Propag., vol. 61, no. 10, pp. 50175027, Oct. 2013.

[9] L. Di Palma, A. Clemente, L. Dussopt, R. Sauleau, P. Potier, and P. Pouliguen, "Circularly-polarized reconfigurable transmitarray in Ka-band with beam scanning and polarization switching capabilities," IEEE Trans. Antennas Propagat., vol. 65, no. 2, pp. 529-540, Feb. 2017.

[10] T. Potelon, M. Ettorre, L. Le Coq, T. Bateman, J. Francey, D. Lelaidier, E. Seguenot, F. Devillers, and R. Sauleau, "A low-profile broadband 32slot continuous transverse stub array for backhaul applications in Eband," IEEE Trans. Antennas and Propag.,vol. 65, no. 12, pp. 6307-6316, Dec. 2017.

[11] W. Rotman, "Wide-angle scanning with microwave double-layer pillboxes," IRE Trans. Antennas Propag., vol. 6, no. 1, pp. 96-105, Jan. 1958.

[12] M. Ettorre, R. Sauleau and L. Le Coq, "Multi-beam multi-layer leakywave SIW pillbox antenna for millimeter-wave applications," IEEE Trans. Antennas Propag., vol. 59, no. 4, pp. 1093-1100, Apr. 2011.

[13] M. Ettorre, F. Foglia Manzillo, M. Casaletti, R. Sauleau, L. Le Coq, and N. Capet, "Continuous transverse stub array for Ka-band applications," IEEE Trans. Antennas Propag., vol. 63, no. 9, pp. 4798-4800, Sep. 2015.

[14] F. Foglia Manzillo, M. Ettorre, M.S Lathi, K. T. Kautio, D. Lelaidier, E. Seguenot, and R. Sauleau, "A multilayer LTCC solution for integrating $5 \mathrm{G}$ access point antenna modules," IEEE Trans. Microwave Theory Tech., vol. 64, no. 7, pp. 2272-2283, Jul. 2016.

[15] Y. She, J. Hirokawa, and M. Ando, "Loss evaluation of post-wall waveguides and its effect on antenna efficiency in millimeter-wave bands," in Proc. IEEE Microw. Conf. Asia Pacific, pp. 2041-2044, Dec 2009, Singapore.

[16] J. Vazquez, M. Shelley, and D. Moore, "Advanced flat panel antennas for small satcom terminals," in $34^{\text {th }}$ ESA Antenna Workshop, Noordwijk, The Netherlands, Oct. 2012.

[17] N. Capet, F. Foglia Manzillo, K. Tekkouk, R. Sauleau, and M. Ettorre, "Guide d'onde multicouche comprenant au moins un dispositif de transition entre des couches de ce guide," PCT/EP2017/076359, Oct. 2016.

[18] F. Foglia Manzillo, M. Ettorre, M. Casaletti, N. Capet, and R. Sauleau, "Active impedance of infinite parallel-fed continuous transverse stub array," IEEE Trans. Antennas and Propag., vol. 63, no. 7, pp. 3291-3297, Jul. 2015.

[19] H. J. Riblet, "The short-slot hybrid junction," Proc. IRE, vol.40, pp.180184, Feb. 1952. 